\title{
A Source for Freire's Philosophy of Human Nature and its Educational Implications
}

\author{
Un recurso principal para la filosofía de la \\ naturaleza de Freire y sus implicaciones educativas
}

\author{
Une source pour la philosophie de la nature \\ humaine de Freire et ses implications éducatives
}

\author{
Fred Harris \\ PhD, University of Manitoba, Canada
}

\begin{abstract}
A major source for Freire's focus on culture in his codifications and, by implication, his pedagogy of the oppressed, has been neglected in the literature: Erich Kahler's work (1943). Kahler's definition of human beings, as beings of discernment and transcendence in contradistinction to animals, forms the backbone of Freire's own views on human nature. In particular, Freire's distinction of being in the world and being with the world as conditions for being a subject of education is derived from Kahler's work. Theoretically, Freire transforms Kahler's separation of humans from non-human animals into a dialectical unity of discernment and transcendence in which each mediates the other, and pedagogically Freire embodies such a unity in the codifications on culture. The separation of humans from non-human animals also grounds Freire's insistence that the curriculum must be formulated on site rather than formulated a priori.
\end{abstract}

Key words: Paulo Freire; Erich Kahler; human nature; animals; codifications; culture; discernment; transcendence.

\section{RESUMEN}

Un recurso principal para la cultura como centro de atención de Freire en las codificaciones e, implícitamente, su pedagogía de los oprimidos, no ha sido tratado en la literatura : la obra de Erich Kahler (1943). La definición de los seres humanos de Kahler, como seres de discernimiento y de transcendencia, a diferencia de los animales, constituye el elemento principal del punto de vista de Freire mismo sobre la naturaleza humana. En particular, la distinción hecha por Freire de estar en el mundo y estar en relaciones con el mundo como condiciones para ser el sujeto de la educación se deriva del trabajo de Kahler. Teóricamente, Freire transforma 
la separación hecha por Kahler de los seres humanos de los animales en una unidad dialéctica de discernimiento y de transcendencia en la cual cada uno media el otro, y pedagógicamente Freire encarna tal unidad en las codificaciones de la cultura. La separación de los seres humanos de los animales constituye también la base para la insistencia de Freire que el programa de estudios debe ser formulado en el sitio en vez de ser formulado a priori.

Descriptores: Paulo Freire; Erich Kahler; la naturaleza humana; los animales; las codificaciones; la cultura; el discernimiento; la transcendencia.

\section{RESUME}

Une source principale pour la culture comme centre d'intérêt de Freire dans ses codifications et, implicitement, dans sa pédagogie des opprimés, a été négligée dans la littérature : l'œuvre de Erich Kahler (1943). La définition de Kahler des êtres humain, comme des êtres de discernement et de transcendance en contraste avec les animaux, constitue le pivot de la vision de Freire lui-même sur la nature humaine. En particulier, la distinction faite par Freire d'être dans le monde et être avec le monde comme conditions pour être un sujet de l'éducation a sa source dans le travail de Kahler. Théoriquement, Freire transforme la séparation faite de Kahler des êtres humains des animaux en une unité dialectique du discernement et de la transcendance dans laquelle chacun sert d'intermédiaire l'un entre l'autre, et pédagogiquement Freire incarne une telle unité dans les codifications de la culture. La séparation des êtres humains des animaux constitue aussi la base de l'insistance de Freire que le programme d'études doit être formulé sur site plutôt que formulé a priori.

Mots clés : Paulo Freire ; Erich Kahler ; la nature humaine ; les animaux; les codifications ; la culture ; le discernement; la transcendance.

\subsection{Educational practice presupposes a theory of human nature}

“All educational practice implies a theoretical stance on the educator's 1 art. This stance in turn implies — sometimes more, sometimes less explicitly — an interpretation of man and the world."

As indicated in the citation above, Paulo Freire argues that different educational philosophies and practices presuppose a characterization of human nature, either implicitly or explicitly. Indeed, since Freire implies that all educational practices involve a vision of what human beings are (whether explicitly or implicitly), different philosophies and practices of education lead to different philosophies of human nature. He also implies that more general vision concerning human nature impacts decisively on educational theory and practice.

\subsection{Recognition by others of the importance of Freire's theory of human nature for his educational theory}

Despite Freire's explicit reference to the importance of a theory of human nature for educational theory and practice, the literature on the subject of Freire's philosophy of human nature in general and its relation to his philosophy of education in particular is relevantly scant. Only a few works have addressed the issue. 
John Dewitt implies that Freire's absolute distinction between humans and nonhuman animals has religious roots. ${ }^{2}$ However, although Dewitt, in one section of his dissertation, focuses on Freire's distinction between human beings and non-human animals (who represent, according to Dewitt, the natural world for Freire), he does not trace how Freire's philosophical anthropology is related to Freire's curriculum theory (or lack thereof). Dewitt, like many others, has implicitly noted only the continuity of Freire's pedagogy (dialogue) with his views on human nature. Furthermore, although he implies that Freire's absolutization of the distinction between human beings and non-human animals has limitations, he explicitly refrains from criticizing this absolutization.

From a decidedly religious point of view, Fausto Franco considers Freire's philosophy of human beings to be central to his educational philosophy. He argues that Freire attempts to convert pedagogy into anthropology and anthropology into pedagogy. ${ }^{3}$ From a religious perspective, he merely reiterates Freire's absolutization of the distinction between human beings and non-human animals. He does not investigate the educational implications of Freire's bifurcation of the human and animal world nor Freire's practices in relation to his philosophy of human nature.

Both works, of course, are limited to Freire's early publications. Later works, with the exception of one dissertation, touch on the issue of Freire's philosophy of human nature less directly. Esther Gottlieb and Thomas La Belle note that Freire's philosophy of human nature forms the backdrop for his educational theory. ${ }^{4}$ They argue that Freire uses the American jeremiad pattern of scripture, with a description of the essential nature of human beings, denunciation of present conditions based on that description and annunciation or prophetic vision. Since Gottlieb's and La Belle's criticism is restricted to the form of Freire's theory, it suffers from a lack of consideration of the adequacy of the content of his philosophy of human nature. Many criticisms of social relations assume some form of the triad, with emphases varying according to the nature of the philosophy, so the triadic structure is insufficient to differentiate Freire's specific philosophy from that of other philosophers.

Again, from a religious point of view, but from a specific vantage point within that view, Peter Jarvis also implies that Freire's theory of human nature has religious roots. ${ }^{5}$ God, according to this view, made the world unfinished, and it is humans' task, if they are to share in the divinity, to contribute to its completion. Freire, of course, denies that this task is ever complete, for if it were, then human nature would be negated. Thus, Jarvis, like many others, considers Freire's philosophical anthropology to have religious roots.

A few critics, therefore, consider Freire's conception of human nature to be vital to his educational theory and, in many instances, connected to his religious convictions.

Like Franco's work, Abraham Abadi's dissertation is a more extended discussion of the relationship between Freire's philosophy of human nature and his philosophy of education. Unlike that work, Abadi does not focus directly on the religious connection to Freire's philosophy of human nature and his educational theory. Rather, he argues that Freire develops a philosophical anthropology that remains a key to his educational theory by implying that Freire relies on Buber's determination of human 
beings as beings who distance themselves from the world and enter into relations with it. ${ }^{6}$ Freire's direct reference to Buber in Pedagogy of the Oppressed, ${ }^{7}$ however, is a reinforcement of a concept of human beings that he had already worked out in earlier works, as I show in this essay. Freire's use of Buber has more to do with the positing of an opposition between Freire's already developed concept of a human being expressed in earlier works and the development of his concept of oppression. Buber explicitly connected up the distancing of human beings and their relating to the world - the I-Thou relation - with its opposite, the I-It relation, and Freire develops this opposition to a greater extent in Pedagogy of the Oppressed.

\subsection{A major source of Freire's theory of human nature not considered in the literature: Kahler}

There is, however, an earlier source for Freire's characterization of human beings as beings who distance themselves from the world and, as a consequence, relate to it (being with the world rather than just being in the world): Erich Kahler's Man the Measure: A New Approach to History. ${ }^{8}$ Freire refers to this work explicitly in his Education for Critical Consciousness when restricting history and culture to humans rather than expanding it to include non-human animals. ${ }^{9}$ The bifurcation of human beings from non-human animals is found in both Kahler's theory and that of Freire.

The following analysis is not meant to be a comparison of Kahler's and Freire's works, but rather is designed to show that Freire's conception of human nature can be interpreted largely in terms of Kahler's definition of human nature and that Freire adapts that definition to his pedagogical and curriculum theory.

\subsubsection{Living beings as separate from human beings}

\subsubsection{Animals as pure beings of the present}

Kahler considers non-human animals to be pure beings of the present or of the immediate present. Although non-human animals live in time, they are not beings of time. They have no consciousness that extends beyond the bare present; their consciousness is therefore devoid of any reference to the future and the past, or at least of any reference that the animal can control:

For, of course, an animal does have a certain kind of memory that is part of its instincts and of its sense reactions. But since it lacks consciousness, it cannot properly register experiences, it cannot recall them at will or abstract from them general conclusions as to how to meet recurring experiences of a similar and yet different kind. ... It is a life in the present with no past and no future. ... But the present of an animal is an overwhelming, all-comprising present, cupped in darkness, a present where there is no consciousness of either birth or death. It is a present so 
stable, so immobile that it is all but identical with permanence, with eternity. ${ }^{10}$

Freire characterizes non-human animals as pure beings in time as well: "A cat has no historicity; his inability to emerge from time submerges him in a totally dimensional 'today' of which he has no consciousness." ${ }^{11}$ Without being able to dimensionalize time, non-human animals cannot objectify the world in which they live, or make it an object to them different from their immediate life or present: "They [animals] live a life without time, properly speaking, submerged in life with no possibility of emerging from it, adjusted and adhering to reality." ${ }^{12}$ They are one with their activity: "... animals ... are unable to separate their 'self' from their activities." 13 They thus lack self-consciousness. They cannot conceive of themselves or their world as different either in the past or in the future. They are thus not beings of time, for to be of time presupposes a progressive transformation within the life of the individual rather than across generations: "Animals ... are immersed in a time which belongs not to them...." 14 The being of non-human animals is the pure present:

Unlike men, animals are simply in the world, incapable of objectifying either themselves or the world. They live a life without time, properly speaking, submerged in life with no possibility of emerging from it, adjusted and adhering to reality. ${ }^{15}$

Pure being in the world involves identifying being and the action of the animal in the pure present. There is no other being to which the animal relates since the animal simply is itself in its actions in the world:

Because of its inability to separate itself from its actions, upon which it is incapable of reflecting, the animal is not able to instill into the transformation which it brings about, a meaning beyond itself. In the measure that its action is a "part" of the animal, the results of the transformation it has brought about do not go beyond it. The results do not become separate since the latter's locus of decision is to be found outside the animal, in the species to which it belongs. ${ }^{16}$

\subsubsection{Animals as beings of contact}

Freire also characterizes non-human animals as beings of contact: "Animals, submerged within reality, cannot relate to it; they are creatures of mere contacts." 17 What Freire means by contact is unclear. Freire's reference to animals as beings of contact may be equivalent to Kahler's characterization of animals as beings who respond to the world primarily through their senses. The animal's senses are windows to the happenings of the world, and it is ever alert to that world via its senses. Its responses to the world are a function of its perception of movement. Its senses need to be alert to the actualization of potential danger, and that actualization is registered through perception of movement, Kahler implies. Its senses do not just respond to movement, but are organs of active search for movement: 
But if you have ever watched a deer or any other wild creature in its native habitat, you have probably noticed that it lives in a state of perpetual vigilance, that it is beset with fears not only of animal foes but of elemental powers as well. A sudden wind, a rustling tree, a distant rumble cause terror and flight. Its senses are sharpened to a degree which in man would be called hysterical. It registers the most minute sensations, the most distant events. It always seems to be in mystical touch with a multitude of potential hovering powers. It must always be on the alert among unknown dangers that may materialize at any moment. ${ }^{18}$

Although there is some memory trace for Kahler, that memory is simply inscribed in the instinctual patterns of the individual member of the species at birth. The memory is not derived from actually living and experiencing the world but from antecedent members of the species that have bequeathed to individual members of specific species certain capacities to respond to the environment in certain ways.

Another reference to the concept of contacts helps clarify it to a certain extent: “... in the life of the animal the expression 'here' denotes nothing but a 'habitat' which he simply contacts." Freire also indirectly explains what the term means when he refers to the habitat as "merely a physical space." Indeed, he considers that "there is no here, now, tomorrow, or yesterday for the animal." ${ }^{19}$ The animal responds to the world immediately present to it through its senses and does not temporalize the environment. It does not relate to the environment consciously; its relations are made a priori or innately rather than chosen consciously.

These interpretations are consistent with Kahler's view of animals as ever alert and responsive to immediate changes occurring in the world via their senses.

Freire may also mean by beings of contact that animals are limited to responding to the facts of a situation rather than to the causes (historical antecedents). This interpretation can be inferred from Freire's comment that the popular masses sometimes remain only at the level of consciousness of facts rather than the causes of those facts. He may also mean by beings of contact that animals do not consciously respond to the possibilities of the facts of the situation. This interpretation can be inferred when Freire points out that it is necessary to note the possibilities of a situation in order to transcend it. ${ }^{20}$ Both interpretations are consistent with Freire's denial that animals are beings of time but rather beings in time since beings in time, but not beings of time, exclude causes (the past) and possibilities (the future) in the present.

The organic structures of animals, formed at birth, Kahler and Freire imply, involves immediate responses to the world by the simple fact of being animals in the world - as beings of contact with immediate stimuli. The cat merely responds to what it has been programmed to respond to at birth, as a member of its species. There is no possibility of individuality at the level of animacy; the cat acts only as a cat and not as this particular cat. It is condemned to act as all cats would act under the same conditions. If the conditions change, then the individual cat will attempt to respond in the same way that all cats respond under similar conditions by adapting passively 
to the changes. Animals, as beings of contact, are egotistical and limited to behaving according to the nature of their species. They are mere instances of their species and not real individuals.

Animals, Freire implies, are purely passive beings since they are mere beings in the world, and all pure beings in the world are purely passive beings, responding to stimuli in a mechanical (routine) manner according to the nature of their species:

They [Jim and Andra, Freire's German shepherds] could not, for example, establish any relationship among the fruits produced by the trees and the birds that, in certain periods of the year, take delight in them and delight us with their songs and their clamor.

Jim and Andra will not perceive the color changes of leaves as a sign of seasonal change. The seasons for them remain at the level of the sensibility toward hot or cold, but they do not have a name to refer to the seasons of the year. Jim and Andra do not speak about these relations. I do not only look and see a tree but I have also the memory of other trees that I can distinguish from those that I see. I do not only speak about trees but I also have the concept tree. ${ }^{21}$

Animals as beings of contact are thus characterized by two traits: they are mere instances of their species - no individual variations in responses arise since any adaptation or modification of responses that does occur is a consequence of the interface of the instincts of the individual animal's species and the environmental conditions then obtaining. The locus for change is located external to the individuals that constitute the species. Animals are also are pure beings in time, or beings of the pure present. The human world, however, is a temporal world, or a world that includes the present, past, and future explicitly.

\subsubsection{Human spirit or praxis, or the unity of discernment and transcendence}

Kahler specifies two elements that differentiate human nature from animals: discernment of objective conditions as limits and the overcoming or transcendence of those limits. Discernment and transcendence as a unity form spirit:

Man's faculty of overstepping his own being is identical with what is understood by the term "spirit." The functions of this faculty are twofold. In the first place, it enables and induces man to discern, and to detach himself from, an outward, contrasting being which is recognized in its own distinct orbit. Or, to be more exact - for the order is rather the reverse — spirit is at first the faculty of detaching and discerning a definite non-self from a definite self. It is the ability to ojectivate and to subjectivate. ${ }^{22}$

For Freire, similarly, authentic praxis or human action involves the unity of discernment and transcendence: 
It is certain that men and women can change the world for the better, can make it less unjust, but they can do so only from the starting point of the concrete reality they "come upon" in their generation. They cannot do it on the basis of reveries, false dreams, or pure illusion.

What is not possible, however, is to even think about transforming the world without a dream, without utopia, or without a vision. Pure illusions are the false dreams of those who, no matter how plentiful their good intentions, propose fancies that cannot be realized. World transformation requires dreaming, but the indispensable authenticity of that dream depends on the faithfulness of those who dream to their historic and material circumstances and to the levels of technological scientific development of their context. ${ }^{23}$

\subsubsection{Discernment}

Discernment involves the separation or objectification of the world and the simultaneous emergence of the subject in relation to the object. Discernment is a necessity for human beings as subjects since it forms the backbone from which they can make intelligent decisions about how they are going to transcend their limiting conditions.

Freire reiterates throughout his life, implicitly or explicitly, the importance of a correct determination of the world for transcendence of limit situations and the humanization of the world. Discernment requires a respect for and search for the truth: "what is expected of those who write with responsibility is a permanent and continuing search for truth...." ${ }^{24}$ Freire repeats in many of his works the need for rigorous discernment of the situation in which people live:

It's important, nonetheless, to stress that the liveliness of the conversation, the lightness of the spoken word, the spontaneity of the dialogue are not in themselves a denial of the serious intent of this work or its requisite intellectual rigour. There are people who have the naïve idea that rigorous analysis can only take place when you shut yourself up within four walls behind a door securely locked with a large key! Only there, in the silent intimacy of library or laboratory can serious scientific work go on! No, I think that here, in privacy, yes, but at the same time open to the world, including the world of nature outside your office, we can engage in serious and rigorous thought — and are doing so. ${ }^{25}$

He does not deprecate the importance of theory and research for an accurate determination of the world:

Lack of rigor or incompetence are not part of the nature of the university's relationship with and commitment to the popular classes. On the contrary, a university that does not fight for more rigor, for more seriousness in its teaching and research (always inseparable) is a university that does not seriously approach popular classes, nor commit to them. ${ }^{26}$ 


\subsubsection{Transcendence, intent or subjectivity}

Freire implicitly uses the concept of transcendence in a way similar to that of Kahler. Kahler in particular uses the term as a defining characteristic of being human: it is the capacity to go beyond oneself physically:

The exclusively human feature we are seeking is to be found not in any partial functioning of the human constitution, but rather in a general quality of man that is the pivot of all the various achievements and manifestations of his civilization, a quality that cannot be localized anatomically or physiologically, but that emerges gradually from the complex totality of the human organism. This is man's faculty of going beyond himself, of transcending the limits of his own physical being. ${ }^{27}$

The transcendental nature of Freire's characterization of human nature, similarly, is encapsulated in his concept of the ontological vocation of human beings: to become more. Human beings are beings of transcendence: a constant process of going beyond their immediately lived world. Transcendence is what Freire refers to occasionally as the "untested feasibility;" it is the exclusively subjective moment of the world.

The determination of the present of human beings, since it involves temporality, involves a past and a future in the present. Past cultural conditions leading up to the present limit situation and the future possibilities of the present limit situation likewise need to be determined. It is necessary to grasp the past in its relation to the present in terms of the limit situations which emerge from the past and that need to be addressed if human beings are to expand their nature as temporal beings. Study of the past thus forms an essential constituent of being human, but of a past that is alive in the present. Intent to transcend is not derived from nothingness. Intent to transcend must be linked to the objective antecedent cultural conditions:

Ultimately, visions of the future are not translated into reality starting from intellectuals in themselves, but from the actual situation they are in. And for that the present must be understood not simply as a present with limitations but also with possibilities. The vision of the future must then be understood as a possibility and as something to be made viable, and not as something readymade. As I have said and written several times on other occasions, historicosocial reality is something given in the sense that it gives itself to us to be shaped, and not something given in final form. ${ }^{28}$

Discernment, as the specification of the past in the present, and transcendence, as the specification of the future in the present (present possibilities, or the untested feasibility), is the exclusive domain of human beings for both Freire and Kahler; the present of non-human animals is thus fundamentally different from the present of human beings. Human beings live in a present that is mediated by the past and the future, or has temporal reference and spread: 
But this present [of animals] is quite different from our present that is lapped in memory and anticipation, that is only a ripple in a vast sea of conscious, half-conscious, subconscious experiences, plans and ideas. Our present is a minute transition from past to future, a continuous flux in the broad current of a known intentional life. ${ }^{29}$

\section{a. Biological transcendence}

The difference in the present of human beings from the present of animals entails a distinction even at the biological level. The difference involves transcendence of conditions assuming two forms, one in which human beings are beings in the world as biological beings and one in which human beings are specifically with the world as social beings. The first form human beings share to a certain extent with animals, such as when humans hunt to meet their biological needs, but there is always a fundamental difference since biological needs of humans always include a present impregnated with a past and a future. In hunting, the treatment of prey is the same in terms of purpose (the need for food), for example, but the methods used are different. Humans, furthermore, can even identify with their prey and convert them into domestic beings. Thus, human beings, in the first form of transcendence, unlike non-human animals, transcend their limitations in the present even in satisfying their biological needs. Transcendence, however, shines brightest in its pure form when the purpose transcends biological need:

Even when man's purpose is the same as the animal's, his method is different. In so far as man uses the animal as a prey, he does not differ from the animal. But in so far as he protects, breeds, studies and loves the animal, he recognizes it as having an orbit of its own, he establishes an orbit separate from his self, an orbit that he can enter deliberately, and thus brings about a new and conscious relationship. This attitude is distinctly human and is made possible only by the faculty of discerning and transcending, the faculty of spirit.

Man's transcending, his overstepping of self, is more easily recognized when not only his methods but his purpose differ from the animal's, as in his disinterested pursuit of art, philosophy, and science. Where man's methods differ from the animal's, his faculty of spirit may be recognized as a fact. Where his purpose differs, spirit has come to be accepted as a value to such a degree that its being and remaining a fact is often forgotten or denied. ${ }^{30}$

The unity and distinction between humans as biological beings and as spiritual beings, indeed, is expressed in Freire's codifications of culture. The first codification of culture, for example, addresses humans as straddling being in the world and being with the world because they share certain needs with those of animals:

By means of simple questions, such as, "Who made the well? Why did he do it? How did he do it? When? which are repeated with regard to the other 
"elements" of the situation, two basic concepts emerge: that of necessity and that of work; and culture becomes explicit on a primary level, that of subsistence. ${ }^{31}$

Unlike non-human animals, even at the biological level, human beings possess culture, but their roots in the animal world are still evident in terms of biological need. The further codifications reinforce the idea and then expand it to include culture as spiritual culture, with a different purpose and subject matter. For instance, the sixth codification of culture, as Paul Taylor points out, ${ }^{32}$ has the artist's signature present in both versions (the original one by Francisco Brennand and the later version by Vincente de Abreu) as a prelude to the symbolic form of patterns on the vase in the seventh codification. Here, however, the difference between subject matter becomes important because the content of the vase is still linked to the material world of humans as beings in the world whereas the content of a poem is linked to the symbolic world that is exclusively human.

Freire, like Kahler, distinguishes material necessity more characteristic of being in the world (biological being) to spiritual necessity characteristic of being with the world (the specifically cultural necessity):

They [the participants in the Culture Circle] discuss whether or not the poem is culture. "It is culture, just as the vase is," they say, "but it is different from the vase." Through the discussion they perceive, in critical terms, that poetic expression, whose material is not the same, responds to a different necessity. ${ }^{33}$

Spiritual necessity involves the aesthetic aspect of being human, or the production of art objects that do not address human need as a biological being (where utility still forms an aspect to consider) but human need stemming from the nature of a being that discerns and transcends the world. In the seventh codification (especially in the original version, where flowers are depicted on the vase), Freire refers implicitly to the distinction of (and indeed divorce between) aesthetic aspects of human culture linked to biological necessity and aesthetic aspects of human culture linked to spiritual necessity, with the latter being the exclusive domain of human nature:

Many participants, referring to the flowers in the vase, say, "As flowers, they are nature. As decoration, they are culture." The esthetic dimension of the product, which in a sense had been awakened from the beginning, is now reinforced. This aspect will be discussed fully in the following situation, when culture is analyzed on the level of spiritual necessity. ${ }^{34}$

Freire splits necessity into material and spiritual necessity, but the specificity of the material content for the former is irrelevant for Freire except in the gross sense of one material form that relates to human need as a being in the world and another material form that relates to human needs as a being with the world, or intersubjective relations.

Human nature finds its most adequate expression in the spiritual form, as a 
meeting of subjects that leave behind utilitarian concerns. The word is the proper form of human transcendence. The vase too expresses human nature as culture, but the vase is still grounded in biological need, or in being in the world. The poem does not address biological necessity (mentioned in the first codification) but rather the necessity of going beyond the human being's own physical being to the general or spiritual needs of human beings. ${ }^{35}$ Poetry expresses transcendence at a higher level than transcendence in the form of the vase because it expresses a purpose that does not relate to the biological world but to the world of beings who can relate to the world; poetry in its very form expresses relations that transcend individual needs that relate to the body, for the form of poetry is the word or the symbol, and symbols as symbols transcend immediate being. It is in the world of art that human beings find their specific nature as human beings, in contradistinction to their biological nature:

Art, on the other hand, is intrinsically personal knowledge, knowledge that is confined to the individual, that proceeds from the individual and is intended for individuals. It is knowledge that in the old religious way is concerned with closed coherence, with perfection, that is essentially perfect. ${ }^{36}$

Furthermore, as art, poetry involves a tendency towards a closed world of coherence at the level of interpersonal relations among individual subjects. This is an ideal that can never be completely realized because humans are still beings in the world, but it is an ideal that human beings can approach by becoming more.

Freire continues to consider culture as a key generative word late in his life: "The first codifications to be 'read,' decodified, by the learners offer possibilities to discuss the concept of culture. To understand culture as a human creation, an extension of the world by men and women through their work, helps to overcome the politically tragic experience of immobility caused by fatalism." ${ }^{37}$ Overcoming fatalism is one of Freire's prime objectives in his pedagogy.

\section{b. The codifications and the context of learning as an expression of Freire's philosophy of human nature}

From the point of the content, Freire incorporates Kahler's bifurcation of human beings from animals as well as his contention that art forms the exclusive domain of the human spirit into his codifications. He also transforms Kahler's distinction of human beings as discerning and transcending beings into an innovative pedagogical form through his codifications. The general structure of the codifications - and not only the codifications on culture - is to enable people (and, later in Freire's career, the oppressed) to come to grasp that they are discerning and transcending beings - that they are subjects.

The need for problem-posing education stems directly from the nature of human beings as not only discerning beings but also transcending beings. The codifications must not assume the form of something finished or fixed from the point of view of the learners, they must, rather, assume the form of something that will likely lead to the 
attempt not only to discern their reality but to transcend it, both in the theoretical context and, eventually, in the practical context:

The task of the educator is to present to the educatees as a problem the content which mediates them, and not to discourse on it, give it, extend it, or hand it over, as if it were a matter of something already done, constituted, completed, and finished. In the act of problematizing the educatees, the educator is problematized too. ... No one can present something to someone else as a problem and at the same time remain a mere spectator of the process. ${ }^{38}$

The practical context, as that which requires transcendence, needs to be mediated by humans' relation to the world as distancing and temporal beings — as discerning subjects. On the other hand, the theoretical context, the purpose of which is to discern the limit situations of the participants, needs to be mediated by the practical context. The codifications and the cultural circles were designed to address simultaneously these two mediating conditions of being human. The theoretical context, or being with the world as a process of gaining distance from the world, contains the concrete context or the being of humans in the world through the codifications of their daily lives so that they can discern their own situation:

The adult literacy process as an act of knowing implies the existence of two interrelated contexts. One is the context of authentic dialogue between learners and educators as equally knowing subjects. This is what schools should be - the theoretical context of dialogue. The second is the real concrete context of facts, the social reality in which men exist. ${ }^{39}$

Being with the world, or the theoretical context (the context of discernment) is hence mediated through the prior process of codification of the practical context.

One of the functions of the codifications is thus to focus attention on the social context within which learning occurs. It is not just a teaching tool for the educator since the content is derived from the students; it is a tool for the learners to participate in the process of the discernment of their own reality, or to welcome them as subjects of their own learning and not as objects:

The camera is a reader of reality, but now it's necessary for us to go into deepening the reading made through the camera in order to put another language in that and to discuss with the group lots of issues that are behind and sometimes hidden. The codification helps the educators and the students to do that. It is a mediation to the discussion. Because of that, the codification was not something to help exclusively the educators. That is, the codification was not an instrument for helping the teacher in his or her speech about the content. The codification is an object to be known, and to the extent that codification represents a part of the concrete reality, in trying to understand or to describe the codification, you are again trying to understand the concrete reality in which you are. ${ }^{40}$ 
Such contextualization provides a necessary antidote to the isolation of the subject matter from the process of humanization, or the isolation of discernment from transcendence and the isolation of transcendence from discernment:

Codification represents a given dimension of reality as individuals live it, and this dimension is proposed for their analysis in a context other than that in which they live it. Codification thus transforms what was a way of life in the real context into "objectum" in the theoretical context. The learners, rather than receive information about this or that fact, analyze aspects of their own existential experience represented in the codification. ${ }^{41}$

On the other hand, Freire's theory requires the opposite movement, where the practical context, or the locus for real transcendence, involves simultaneously the mediating presence of the theoretical context of discernment:

In the last analysis, the themes both contain and are contained in limit-situations, the tasks they imply require limit-acts. When the themes are concealed by the limit-situations and thus are not clearly perceived, the corresponding tasks - people's responses in the form of historical action - can be neither authentically nor critically fulfilled. In this situation, humans are unable to transcend the limit-situations to discover that beyond these situations - and in the contradiction to them - lies an untested feasibility. ${ }^{42}$

The decodification process, if it is effective, should enable the oppressed to grasp their world critically as a world that denies them the power to discern and transcend the world and simultaneously enables them to discern the world as their world - a world in which they, along with many other generations, involves transcendence of their limit situations.

\subsubsection{Differences between Kahler's and Freire's conception of the human spirit}

Although Freire's theory of human nature borrows heavily from that of Kahler, his theory is not identical to that of Kahler. For Kahler, spirit is not reducible to pure reason but involves an emotional element:

This quality [human spirit] ... does not coincide with reason, for it manifests itself not only intellectually but emotionally. It is this faculty, for instance, that makes man capable of the true love based on choice and affecting his whole existence, of love regardless of recompense. ${ }^{43}$

As Ann Sherman points out, ${ }^{44}$ Freire's views on emotions are ambivalent - to say the least. In the codifications, one of the criteria for the selection of generative words 
and themes is their emotional nature for the participants. Freire thus implicitly and at a practical level recognizes the importance of emotions in engaging human beings - human selves or subjects - with the world, or with providing the energy and focus necessary to engage in the process of discernment that leads to transcendence. On the other hand, he also opposes emotions to reason in the process of discernment, with emotions becoming less and less efficacious as the process of discernment advances.

Freire implies in several places that discernment and transcendence, on the one hand, and emotions, on the other, are mutually exclusive. In referring to Urban's theory of communication and approving of it, Freire evidently considers communication of emotion and cognition of objects to be mutually exclusive:

According to him [Urban], these acts [of communication] occur basically on two levels. On one level the object of communication belongs to the sphere of emotion. On another level knowledge is communicated. In the first case (which is of no concern in this essay) communication manifested on an emotive level "operates by contagion." In this type of communication one of the Subjects evokes a certain emotional state in another (fear, joy, hate, etc.), and can be influenced by this state. Alternatively s/he can get to know this state in the Subject manifesting it. However, in this kind of communication, which is also found at an animal level, there is no "entering into" the object by the communicating Subjects. ${ }^{45}$

Emotions are more akin to the animal level and hence are, Freire implies, to be avoided or suppressed at the human level. The emotional level has no object that mediates between the subjects and hence is not intellectual (or human) nor critical at all whereas human communication always involves a meaningful object between knowing subjects:

The "entering into" the object of communication, expressed by linguistic signs, is the second type of communication distinguished by Urban. Here communication operates between Subjects about something which mediates them and which is "offered" to them as a knowable fact. ... true communication is not ... the exclusive transfer or transmission of knowledge from one Subject to another, but rather his co-participation in the act of comprehending the object. It is communication carried out in a critical way. On an emotive level communication can take place both between Subject "A" and Subject "B," and between a crowd and a charismatic leader. Its main characteristic is to be a-critical. ${ }^{46}$

Emotion, having no real object, is not real or human communication but pseudocommunication. It has the form of communication, but without the content of a linguistic sign that form is empty of meaning.

Freire, in fact, explicitly denies that there is an identity between his conception 
of spirit and that of Kahler. ${ }^{47}$ Freire's exclusion of emotion from spirit probably constitutes one of the reasons for his differentiation of his concept of spirit from that of Kahler.

\section{Conclusion}

This article has shown that Kahler's model of human nature - the unity of discernment and transcendence - can be used to interpret a large part of Freire's own model of human nature. Human beings are both discerning and transcending beings for Kahler and Freire, and these traits fundamentally separate human beings from the animate world. Freire, however, applies such a model in an innovative manner to the educational context of situations of oppression in terms of the codifications of culture and in terms of the dialectical mediation of the theoretical or educational context of discernment through the existential conditions to be transcended and the dialectical mediation of the existential conditions to be transcended through the theoretical or educational context of discernment.

Undoubtedly, there are many other influences that inform Freire's model of human nature, but Kahler's model, which has gone unnoticed in the literature, is certainly central to Freire's own model and pedagogical project.

\section{Notes}

1. Paulo Freire, Cultural Action for Freedom (Cambridge, MA: Harvard Educational Review, 1970), 6.

2. John Dewitt, "An Exposition and Analysis of Paulo Freire's Radical Psycho-social Andragogy of Development" (PhD dissertation, Boston University School of Education, 1971), 71.

3. Fausto Franco, El Hombre: Construcción Progresiva: La Tarea Educativa de Paulo Freire (Madrid: Marsiega, 1973), 47-81, 149-50, 167.

4. Esther Gottlieb and Thomas La Belle, "Ethnographic Contextualization of Freire's Discourse: Consciousness-raising, theory and practice," Anthropology \& Education Quarterly 21, no. 1 (1990): 3-18.

5. Peter Jarvis, "Paulo Freire: Educationalist of a revolutionary Christian movement," Convergence 20 (1987): 30-41.

6. Abraham Abadi, The Philosophical Anthropology of Paulo Freire (PhD dissertation, Boston University, School of Education, 1982), 38-58.

7. Paulo Freire, Pedagogy of the Oppressed. New Revised $20^{\text {th }}$ Anniversary Edition (New York: Herder and Herder, 1993), 148.

8. Erich Kahler, Man the Measure: A New Approach to History (New York: Pantheon, 1943).

9. Paulo Freire, Education for Critical Consciousness (New York: Seabury, 1973), 3.

10. Kahler, Man the Measure, 32-3.

11. Freire, Critical Consciousness, 3. 
12. Freire, Cultural Action, 28.

13. Paulo Freire, "Cultural Freedom in Latin America," in Human Rights and the Liberation of Man in the Americas, ed. L. Colonnese (Notre Dame: University of Notre Dame Press, 1970), 165.

14. Freire, Cultural Action, 31.

15. Ibid., 28.

16. Freire, "Cultural Freedom," 165.

17. Freire, Critical Consciousness, 3.

18. Kahler, Man the Measure, 32.

19. Freire, "Cultural Freedom," 166.

20. Paulo Freire and Antonio Faundez, Learning to Question: A Pedagogy of Liberation (New York: Continuum, 1989), 48, 55.

21. Paulo Freire, Pedagogy of the City (New York: Continuum, 1993), 108.

22. Kahler, Man the Measure, 11.

23. Paulo Freire, Pedagogy of Indignation (Boulder, CO: Paradigm Publishers, 2004), 32.

24. Paulo Freire, Letters to Cristina: Reflections on My Life and Work (New York: Routledge, 1996), 2. Anthony Petruzzi, "Between Conventions and Critical Thinking," Journal of Advanced Composition 18, no. 2 (1998): 309-32, claims that Freire does not advocate an objectivist view of truth. Freire certainly does not agree with such a view if by objectivist is meant that truth is somehow to be determined for its own sake, or if it is meant that reality is somehow static. However, there are just too many passages in Freire's works where he refers to the need to increasingly penetrate reality or to unveil it, not as something static, but as a continual process of discernment, transcendence through action and discernment once again in a changing context.

25. Freire \& Faundez, Learning to Question, 3.

26. Freire, Letters to Cristina, 132.

27. Kahler, Man the Measure, 11.

28. Freire \& Faundez, Learning to Question, 55.

29. Kahler, Man the Measure, 32.

30. Kahler, Man the Measure, 12-3.

31. Freire, Critical Consciousness, 63. Paul Taylor, The Texts of Paulo Freire. (Buckingham, PA: Open University Press, 1993), 88-92 argues that the first codification can be interpreted in various ways but that Freire directs the interpretation of the codification in a particular way. This direction, Taylor implies, contradicts Freire's own view that human beings are subjects and not objects. That Freire wants the learners to interpret the codification in the way that indicates that they are subjects is evident: "They perceive the normal situation of man as a being in the world and with the world, as a creative and re-creative being who, through work, constantly alters reality" (Freire, Critical Consciousness, 63). As Peter Lownds argues, In the Shadow of Freire: Popular Educators and Literacy in Northeast Brazil (PhD dissertation, University of California, Los Angeles, 2005), 119, to construe Freire's codifications, which affirm that peasants are subjects and that even recognizes subjectivity at the biological or animal level of basic needs, as manipulative is to fail to understand the need for such affirmation in the context of a society where human beings have been systematically treated as objects. However, Freire's codifications may have been manipulative by being inadequate to Freire's claims of their efficacy. That issue, though, goes beyond the bounds of this essay. 
32. Taylor, Texts, 111-12.

33. Freire, Critical Consciousness, 77.

34. Ibid., 75.

35. Since spirit also has religious connotations for Freire, spiritual necessity may also mean the need to approach God through intersubjective relations.

36. Kahler, Man the Measure, 495.

37. Freire, Letters to Cristina, 128.

38. Freire, Critical Consciousness, 153.

39. Freire, Cultural Action, 14.

40. Miles Horton and Paulo Freire, We Make the Road by Walking: Conversations on Education and Social Change (Philadelpia, PA: Temple University Press, 1990), 88-9.

41. Freire, Cultural Action, 15.

42. Freire, Pedagogy of the Oppressed, 83.

43. Kahler, Man the Measure, 11.

44. Ann Sherman, "Two Views of Emotion in the Writings of Paulo Freire," Educational Theory 3, no. 1 (1980): 35-8.

45. Freire, Critical Consciousness, 140.

46. Freire, Critical Consciousness, 140-41.

47. Paulo Freire, "Conscientização e alfabetização — uma nova visão do processo," Revista da Cultura da Universidade de Recife 4 (1963): 5-23. 